\title{
Eye movements during search for coded and uncoded targets
}

\author{
S. M. LURIA and MARK S. STRALSS \\ Naval Submarine Medical Research Laboratory, Naval Submarine Base, Groton, Connecticut 06340
}

Eye movements and search time of four subjects were studied as they searched for a target dial in a $4 \times 4$ array of dials which were differentiated by (1) color, (2) shape, (3) a combination of color and shape, or (4) were uncoded. Subjects did not exhibit a characteristic scanpath, and method of scanning did not relate to search time. Search time varied reliably among conditions; it was generally shortest in the color condition, followed by color shape, shape, and the uncoded condition. Subjects were capable of using both shape and color simultaneously. Search time was strongly associated with the average number of fixations required for target detection but not with other measures of eye movements. Fixation duration was a particularly inconsistent measure.

Noton and Stark (1971a. b) have reported that a given individual will show a reliable pattern of eye movements under different viewing conditions. Gould and Peeples (1970) have noted that each subject generally uses the same scanning pattern throughout an experiment. Locher and Nodine (1974) have found that at least some subjects exhibit a characteristic scanpath when perusing a given random shape. But it is not clear if differences in visual search patterns are related to differences in searching performance. That is. do individuals who can quickly search out targets have distinctive scanpaths compared to less efticient searchers:"

A second set of questions is concerned with the effects of the stimulus variables. Is an individual who is good in one condition also good in other conditions? Little is known about how the character of the nontarget stinuli affects the search for the target. There have been a number of studies which have investigated search time as a function of the amount of information available or the amount of irrelevant information (Archer. 1954; Baker. Morris and Steedman, 1960; Christner \& Roy, 1961; Eriksen. 1952; Hitt. 1961; Green \& Anderson. 1956; Newman \& Davis, 1962; Smith, 1962), but only Williams (1966. 1967, 1973) appears to have studied fixation errors with coded stimuli: that is, if the subject is looking for a blue target. are certain nontarget colors looked at more often than others?

The purposes of this study were to investigate the effects of coding dials by color, shape, and a combination of the two on (1) eye movements and (2) efficiency in finding a target dial. We also sought to determine if subjects have a reliable pattern of scanning under a given set of conditions; whether the

This research was conducted under Bureau of Medicine and Surgery. Nary Department. Research Work Unit M4305.08$3001 \mathrm{DAC} 9$. pattern remains stable when the conditions are changed. and if there is a relationship between pattern of scanning and the time needed to find a target dial.

\section{METHOD}

\section{Subjects}

Four staff members of the laboratory participated as subjects. All had 2020 uncorrected vision and normal color vision.

\begin{abstract}
Apparatus
The subject sat behind a shutter with his head in a chinrest $60 \mathrm{~cm}$ from a panel of 16 white dials $\left(6.2^{\circ}\right.$ wide $x 5.7^{\circ}$ high) arranged in a $4 \times 4$ rectangular array $\left(60^{\circ} \times 34^{\circ}\right)$. The vertical separation of the dials $u$ as $3.75^{\circ}$ and the horizontal separation was $12^{\circ}$. A red light in the center of the array was the only thing visible through a small aperture in the shutter. It served as a continuously visible fixation point in the plane of the array. Ambient illumination was provided by tluorescent ceiling lights.

To color-code the dials ( $C$ condition), a sheet of white cardboard with cutouts for the dials and light could easily be positioned over the panel. since the dials protruded about $1.5 \mathrm{~cm}$ from the background. Each cutout was outlined with a $1.2^{\circ}$ band of blue. red. green. or yellow. Each color appeared randomly in four locations on the sheet. Sixteen different sheets were constructed. During the experiment. the sheets rested on the dials, one in front of the others. Each sheet could be instantly removed. Thus, on each trial. the subject was faced with a different random arrangement of coded dials.

Another series of sheets was prepared to code the dials by shape ( $S$ condition). Each dial was centered in a rectangle (called "square"). a diamond, an $\mathrm{X}$, or a + made of $1.2^{\circ}$-wide black bands. On each trial. each shape appeared four times in a different random arrangement.

A final set of 16 sheets was prepared to code the dials both for color and shape (CS condition). Each color and shape appeared about once at each dial. A different sheet was made for each possible target stimulus. For example, for the "blue diamond" target. the display contained four blue diamonds located randomly, a diamond in each of the other three colors, each of the other three shapes in blue (the target color), and a random choice of the remaining three colors and shapes for the other six dials. Thus. 7 of the 16 dials were the target color.

Eye movements were measured with a Biometrics Inc. eye-movement monitor. Model SGHV-2, and recorded on magnetic
\end{abstract}


tape by a Hewlett-Packard FM instrumentation recorder, Model 3960. Paper records were made with a Bolt Beranek and Newman Plotamatic $X-Y$ recorder and a Houston Instruments Omnigraphic strip chart recorder, Model 3000 . Search times were recorded on line with a Lafayette Instrument Co. clock-counter. Model 54417.

\section{Procedure}

To start a trial, the experimenter selected the predetermined target dial. If it was a coded condition, he announced the color, or shape. or combination of color and shape of the target dial just before he opened the shutter. If it was the uncoded (U) condition, he simply opened the shutter and pressed the "start" button. This turned on the red light and timer, signaled the recorder, and caused the pointer on every dial except the target dial to move one-third of the full scale deflection. The subject's task was to find the dial which had not been activated as fast as possible. As soon as he did. he pressed a button which returned every dial to zero, stopped the timer. turned off the red light, and signaled the recorder that the trial was over. The experimenter closed the shutter, and the subject reported the number of the target dial to ensure that he had found the correct one. The coded sheet was removed to set up the next arrangement, and the sequence was started again with the next target dial.

A session consisted of 64 such trials; each dial was the target four times, in random order. There were four sessions, with the four conditions counterbalanced among the four subjects. A different random order was used in every session.

\section{RESULTS}

\section{Search Time}

The mean times required by each subject to find the target dial under the various conditions are given in Table 1. Coding by shape produced virtually no mean change in search time. Coding by color resulted in a mean decrease of $51.4 \%$ in search time; every subject
Table 1

Mean Search Time (Seconds) for Each Subject in Each Condition

\begin{tabular}{ccccc}
\hline Subject & Uncoded & Color & Shape & $\begin{array}{c}\text { Color- } \\
\text { Shape }\end{array}$ \\
\hline T. P. & 2.56 & 1.25 & 2.30 & 1.75 \\
C. M. & 2.76 & 1.11 & 2.41 & 1.70 \\
E. H. & 2.68 & 1.20 & 2.29 & 1.62 \\
J. W. & 2.20 & 1.49 & 3.17 & 3.09 \\
Mean & 2.55 & 1.26 & 2.54 & 2.04 \\
\hline
\end{tabular}

Table 2

Mean Number of Fixations Required by Each Subject to Find the Target in Each Condition

\begin{tabular}{ccccc}
\hline Subject & Uncoded & Color & Shape & $\begin{array}{c}\text { Color- } \\
\text { Shape }\end{array}$ \\
\hline T. P. & 7.75 & 2.47 & 4.97 & 2.86 \\
C. M. & 9.61 & 2.56 & 4.98 & 3.14 \\
E. H. & 9.83 & 3.50 & 6.86 & 4.31 \\
J. W. & 5.33 & 2.50 & 6.19 & 5.30 \\
Mean & $\mathbf{8 . 1 3}$ & 2.76 & 5.75 & 3.90 \\
\hline
\end{tabular}

found the color-coded dials in the shortest time. Coding by color and shape resulted in a mean decrease in search time of $20 \%$. Three subjects found these dials in the second shortest time and took longest to tind the uncoded target dials. Analysis of variance showed these differences between conditions to be reliable $(F=9.60, \mathrm{p}<.003)$.

A breakdown of the search times according to specitic colors and shapes showed that three subjects found targets coded yellow or red faster than those coded blue or green. Three subjects found the targets
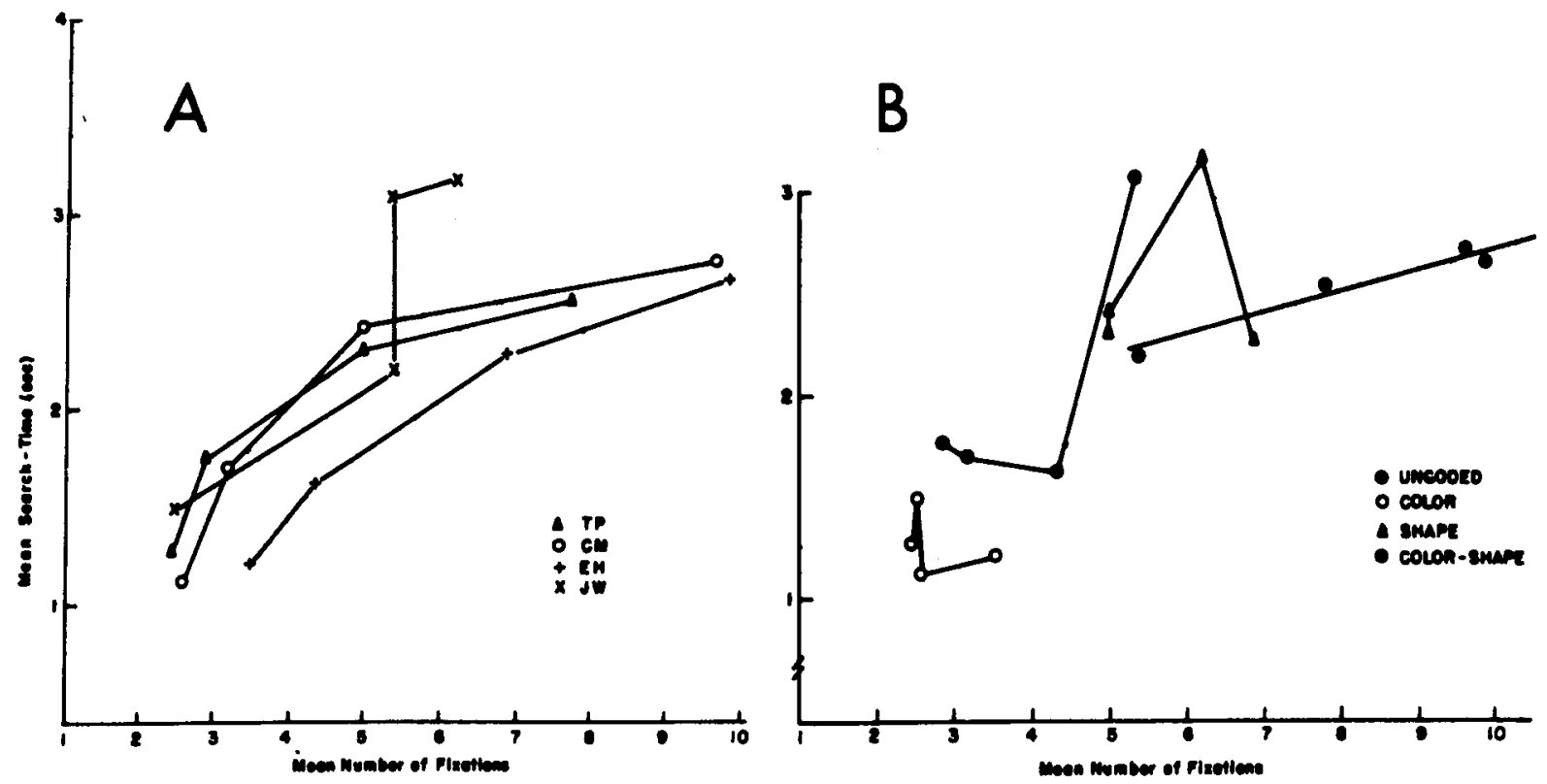

Figure 1. Mean search time as a function of mean number of fixations for each subject in the various conditions (A) grouped by subject, and (B) grouped by condition. 
coded with a rectangle or diamond faster than those coded with $\mathrm{X}$ or + : all did so in the CS condition. Search times were increased (mean increase = -- sec) for every subject when shape was added to color but decreased (mean decrease $=.51 \mathrm{sec}$ ) when color was added to shape.

\section{Number of Fixations}

The mean number of fixations required by each subject to find the target under the various conditions is given in Table 2. All subjects required the fewest fixations to find the color-coded dials and the next fewest to find the dials coded by both color and shape. Three subjects required the most fixations to find the uncoded dials. These differences between conditions are reliable $(\mathrm{F}=13.8, \mathrm{p}<.001)$.

It is obvious. from Tables 1 and 2 , that there is a very close relationship between mean search time under a given condition and mean number of fixations. Indeed, the correlations range from .88 to $.9^{-}$for the individual subjects: Figure $1 \mathrm{~A}$ shows this relationship. grouped by subject across the four conditions. Search time for any given subject from one condition to another is explained to a great extent simply by the number of fixations he had to make. When, however. the results are grouped by condition (Figure 1B). it shows that there is a linear relationship among subjects only in the uncoded condition. In the coded conditions. search time apparently does not depend merely on number of fixations, and number of fixations does not predict how a subject will compare with other subjects.

\section{Nontarget Fixations}

The effectiveness of the coding is further clarified by the pattern of fixations to nontargets. Figure 2 shows the percentage of tixations on dials coded by a given color or shape (or both) as a function of the coding of the target dial in the various conditions. For example. when the dials were coded by color alone and the target was blue. $64 \%$ of the fixations were on blut dials: when the target was green. $63 \%$ of the lixations were on green dials. On the average. $69 \%$ of the fixations made in this condition were on the target color. Color is thus an effective attention-getter. The most effective colors were red and yellow, in conformance with the results of the search-time analysis. Interestingly, for each target color the percentage of fixations drops progressively as the nontarget color is further removed along the spectrum from the target color. This effect occurred in 13 of the 16 possible instances and contirms the findings of Williams (1973).

When the dials were coded by shape, the target-shape again evoked the greatest percentage of fixations. but the mean percentage was only $41 \%$ of the total. Shape was thus a less effective coding device

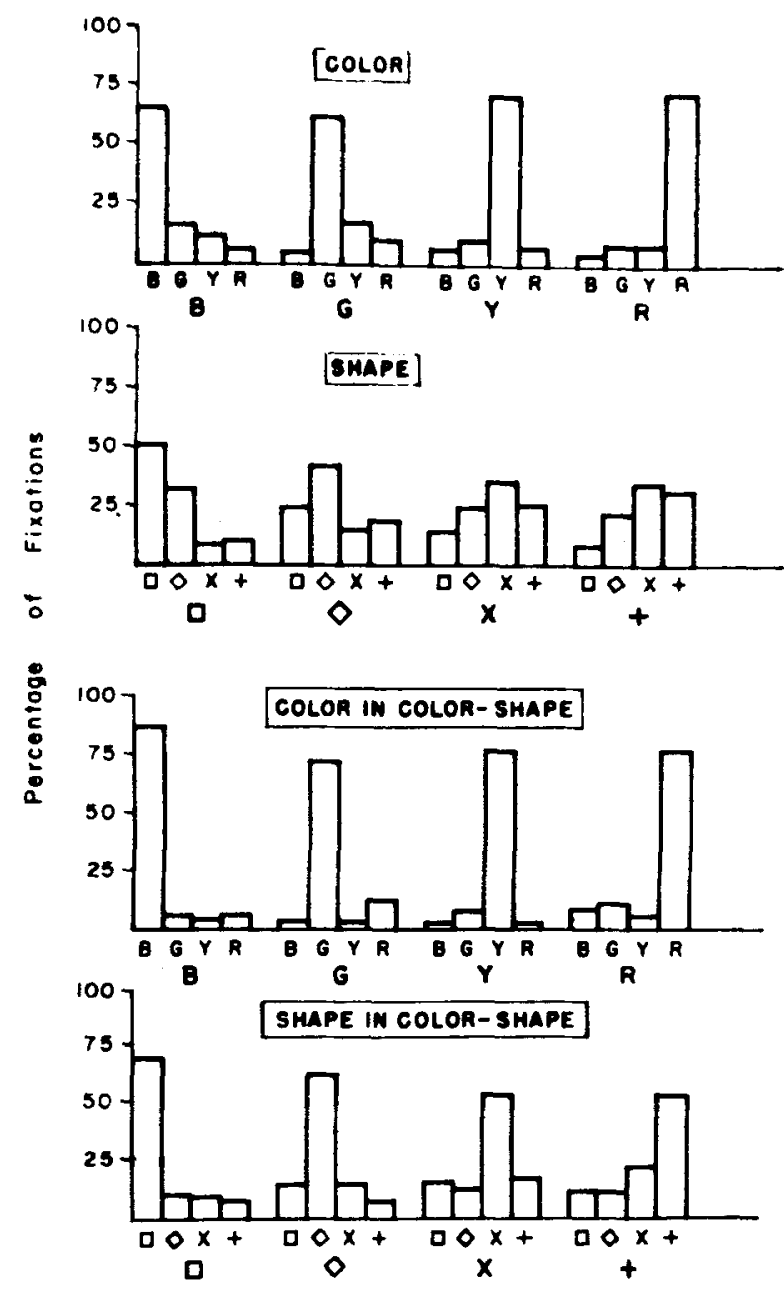

Figure 2. Percentage of fixations on dials coded by a given color or shape as a function of coding of the tanget dial. The target is indicated by the larger symbols under each section of the graph.

than color. The most effective shape was the square. followed by the diamond. The $X$ and + were much less effective. each eroking only about $35 \%$ of the tixations. These results also agree with the search-time data.

An analysis of the fixations in the CS condition. given in Table 3. shows that the subjects were responding to both color and shape. Disregarding the correct shape. $84 \%$ of the nontarget fixations were made to the correct color; conversely, $70 \%$ of the

Table 3

Mean Percentage of Total Fixations on the Correct Color Averaged Over All Shapes and on the Correct Shape Averaged Over All Colors When Targets Were Identified by Both Color and Shape

\begin{tabular}{llll} 
B & 88 & 0 & 78 \\
G & 80 & 0 & 75 \\
Y & 85 & $X$ & 62 \\
R & 84 & + & 65 \\
\hline
\end{tabular}


Table 4

Comparison of the Various Measures of Coding Effectiveness

\begin{tabular}{|c|c|c|c|c|}
\hline Measure & Uncoded & Color & Shape & Color-Shape \\
\hline Mean search time (sec) & 2.56 & 1.26 & 2.54 & 2.04 \\
\hline Initial reaction time (sec) & .28 & .24 & .24 & .24 \\
\hline Mean number of fixations & 8.13 & 2.76 & 5.75 & 3.90 \\
\hline Mean number of one-fixation trials & 8.5 & 23.0 & 13.8 & 18.0 \\
\hline Nontarget fixations (percent) & & 31 & 59 & 48 \\
\hline Mean fixation duration (sec) & .17 & .21 & .21 & .23 \\
\hline Duration of one-fixation trials (sec) & .77 & .65 & .79 & .76 \\
\hline Final fixation time (sec) & .27 & .31 & .34 & 37 \\
\hline
\end{tabular}

nontarget fixations were made to the correct shape. Although shape was not as good a code as color, the subjects were responding rather effectively to it. If a fixation was required to be on both a given color and shape to be classified as correct, then $53 \%$ of the nontarget fixations were correct.

\section{Other Measures}

Several other aspects of the eye-movement data were analyzed to see how consistently they conformed to the search-time results. We would expect a short search time to be associated with a short reaction time, a small number of fixations, a large percentage of trials on which the target was found on the first fixation. a low percentage of nontarget fixations, and $s$ short fixation duration. Table 4 shows that all these measures are consistent except for those relating to fixation duration.

\section{Scanning Patterns}

Having plotted the individual fixations, we next considered whether the subjects exhibited characteristic. reliable scanpaths. In general, we could not discern any. Except for 2 of the 16 sessions, all subjects appeared to search randomly.

Some indication of the degree to which a search pattern was systematic is given by the ratio of the number of fixations to the dial which was looked at most often to the number of fixations to the dial which was looked at least. If the search is random, this ratio should be unity. A higher ratio indicates a less random search. Table 5 shows that C.M. and E.H. carried on a systematic search in the $U$ condition.

Table 5

Ratios of Largest Number of Fixations on a Dial to the Smallest Number of Fixations on a Dial During Each Condition for Each Subject

\begin{tabular}{crccc}
\hline Subject & Uncoded & Color & Shape & $\begin{array}{c}\text { Color- } \\
\text { Shape }\end{array}$ \\
\hline T.P. & 1.65 & 1.86 & 1.67 & 3.80 \\
C. M. & 10.83 & 4.75 & 2.89 & 4.80 \\
E. H. & 9.00 & 3.50 & 1.85 & 2.30 \\
J.W. & 3.44 & 7.00 & 2.69 & 2.83 \\
Mean & 6.23 & 4.28 & 2.28 & 3.43 \\
\hline
\end{tabular}

(J.W. 's high ratio during the color condition resulted from a tendency to avoid scanning the lower row of dials.) These differences are not statistically reliable, but it may be noted that the ratios are always lowest in the $S$ condition.

We have calculated correlations between regularity of scanning and search time both for each condition pooled over subjects and for each subject pooled over conditions. Most of them were positive, but they were not high enough or consistent enough to conclude that there is a relationship.

\section{DISCUSSION}

\section{Scanpaths}

Our first question was, do subjects have characteristic scanpaths, and are scanpaths related to efficiency of performance? As a general rule, our subjects did not exhibit reliable patterns of scanning as they searched the array, although two subjects did search systematically when the dials were uncoded. ${ }^{2}$ Scanning in this task was thus different from that found during repeated perusal of patterns (Noton \& Stark, 1971a, b) and for subjects matching eight figures to a central standard (Gould \& Peeples, 1970). The latter noted that "although different Ss scanned patterns in different orders, each $S$ generally used the same scan pattern throughout the experiment" (p. 54). Their experiment was most comparable to our $U$ condition, and suggests that whether a subject scans systematically or not depends on the particular task or conditions.

There was no indication that systematic scanning was related to speed of target detection. Locher and Nodine (1974) have recently found that characteristic scanpaths do not improve recognition of random shapes.

A related question has to do with the relationship between speed of target detection and speed of scanning. Gould and Dill (1969), for example, reported that fast scanners tend to make fewer fixations of shorter duration. Defining a fast scanner as one who finds the target quickly (as Gould and Dill did), we found a relationship between search time and number of fixations only for the $U$ condition: subjects 
who found the target quickly made few fixations. There was no relationship in the other conditions (Figure 1B). In fact, when the subjects' performances were averaged over conditions, the one who had the fastest mean search time had the most fixations.

On the other hand, fixation duration was quite different. In the $U$ condition, long fixation durations were associated with short search times; in the other conditions, the opposite was true (Figure 1A). The latter seems reasonable; we have no explanation for the former.

\section{Effect of Coding}

The second question concerned the effect of the stimulus variables. Search time was considerably reduced for three subjects when the dials were coded. Color was the most effective coding, as many investigators have found before (Christner \& Roy, 1961; Egeth, 1969; Eriksen, 1952; Hawkins, 1969; Hitt, 1961; Lappin, 1967; Newman \& Davis, 1962; Snith, 1962; Stone, 1971a, b; Williams, 1966). For our particular stimuli, red and yellow were the more effective colors. Williams (1973) found that the largest percentage of fixations was to orange targets. Green was typically the worst color. In the CS condition, for example, green attracted the smallest percentage of total fixations; in the $\mathrm{C}$ condition, it produced the longest reaction times, the largest number of fixations, and the largest number of nontarget fixations. These results conform to those of a large number of studies on the visibility of colors in the periphery which show that green has the smallest area of retinal sensitivity (Connors \& Kelsey, 1961; Connors \& Kinney, 1962) and that its visibility deteriorates relatively rapidly under adverse viewing conditions (Boynton. Schafer, \& Neun, 1964; Luria, 1967; Weissman, 1965; Weitzman \& Kinney, 1969).

Shape, even at its best (the square), was a much less effective code than color by virtually every criterion. In addition, there were much greater differences between the various shapes than between the colors for almost every measure.

When shape and color were both used. performance measures were typically intermediate between those for color or shape alone. This suggests that subjects may have been using only color as the code and were distracted to some extent by the shapes. Stone (1971a) found that all his subjects were slowed by the presence of irrelevant shape information and unable to ignore it. Eriksen (1952) also pointed out that certain combinations of codes may make judgments more difficult. Postman and Bruner (1949) found that subjects were slowed by multiple sets in identifying words. Green and Anderson (1956) concluded that irrelevant color information degraded performance. And Newman and Davis (1962) concluded. from their very complex experiment, that combinations of two or three levels of three codes degrade performance, particularly when one of the codes is thash rate. It should be noted, however, that tlash rate is a particularly difficult code to identify (Cook \& Beazley, 1962). And Smith (1962) did not contirm Green and Anderson's results, which he attributed to the illusion of chromostereopsis. Williams $(1966,1973)$ concluded that when targets are specitied by more than one characteristic, subjects tend to ignore the less effective one. Weitz (1947) and Grant (1951) concluded that compounding stimulus differences improves discriminability.

To determine if our subjects were able to utilize more than one code at once, a correction must be made for the fact that in the $C$ and $S$ conditions, only four dials were the target color or target shape, whereas in the CS condition there were seven dials which were either the correct color or the correct shape. Assuming, for simplicity, that the decrease in effectiveness is a linear function of the additional dials to be scanned, we would expect search time in the $C$ condition to increase from $1.26 \mathrm{sec}$ (see Table 3 ) to $2.22 \mathrm{sec}$ in the CS condition. It increased only to $2.04 \mathrm{sec}$. Similarly, the number of fixations-which should have increased to 4.86 -increased only to $46 \%$, rather than $55 \%$. And the percentage of one-fixation trials-which should have decreased from $23 \%$ to $13 \%$-decreased to only $18 \%$. We conclude, therefore, that the subjects were in fact using both characteristics, and that if the number of relevant dials were the same in both the $C$ and $C S$ conditions, it is possible that search times would have been shorter in the CS condition.

Table 2 breaks down the fixations in the CS condition according to both codes. It is quite clear that the subjects' fixations were governed by both. For example, when the target was a square, $78 \%$ of the fixations were on the square, irrespective of the target color. Even when the target was an X, 62\% of the fixations were on the correct shape. What is not completely clear is whether the double coding was always a help. Color added to shape certainly improved performance, but the effects of shape added to color are not certain.

\section{Fixation Duration}

The failure of fixation duration to conform to the other measures is of interest. Gould and Dill (1969) reported the same finding and wondered if it indicated that fixation duration was not an appropriate measure of performance. The present results indicate that fixation duration is not an important predictor of efficiency of search. It accounts at most for only a small fraction of the variance. The results therefore conform with those found in studies of reading. Tinker (1951) noted long ago that fixation duration is a poor predictor of 
reading proficiency, in contrast with number of fixations which is fairly valid as a measure of speed of reading proticiency.

Despite its lack of consistency with the other measures, fixation duration is apparently indicative of at least some of the cognitive processes occurring. It is, for example, reliably less for uncoded dials and tends to be longer for dials coded by color or shape, and thus presumably reflects encoding time. Similarly. Tinker reported that fixation duration is about $220 \mathrm{msec}$ for each prose, about $236 \mathrm{msec}$ for scientific prose. and even longer for reading objective test questions.

\section{REFERENCES}

ARChER. E. J. Identitication of visual patterns as a function of information load. Joumal of Experimemal Psychology, 1454. 48. 313.31?

Baker. C. A., Morris, D. F., \& Steedman, W. L. Targetrecognition on complex displays. Human Factors, 1960, 2. $251-201$.

Boynton. R. M.. Schafer, W., \& Neun, M. Hue-wavelength relitions nwasured by color-naming methods for three retinal fwations. Sciencic. 1904, 146, 606-668.

Christner, C. A.. \& Roy, H. W. An evaluation of the effect of sclected combinations of target and background coding on map-rading performance: Experiment V. Human Factors. 1961. 3. $131 \cdot 146$.

Connors. M. M.. \& Kelsey. P. A. Shape of the red and green colur zone gradients. Journal of the Optical Society of Americu, 1961, 51. 874-877.

Connurs, M. J.. \& Kinney, J. A. S. Relative red-green sensilivity as a function of retinal position. Journal of the Oprical Sociery of Americu. 1962. 52. 81-84.

Cook. K. G., \& Beazley. L. M. Determination of identitiable light tlash patterns. Journal of Engineering Psychology, 1962. 1. 14.25 .

Egeth. H. E. Parallel versus serial processes in multidimensional vimulus dixcrumination. Perception \& Psychophysics, 1969. 1. $245-252$.

Eriksen. C. W. Location of objects in a visual display as a function of number of dimensions in which the objects ditfer. Jominal of Experimental Psychology, 1952, 44, 56-60.

Govid. J. D.. \& Dill. A. B. Eye-movement parameters and pattern discrimination. Perception \& Psychophysics, 1969. 6. $311-320$.

Ciolito. J. D. \& Pfeptes. D. R. Eye movements during visual watch and discrimination of meaningless. symbol, and objective pattems. Journal of Experimental Psychology, 1970, 85. 51.55.

GRANT. D, A. Perceptual versus analytical responses to the number concept of a Weigl-type card sorting test. Journal of Exprefimental Psichology: 1951. 41, 23-29.

Green. B. F.. \& Anderson, L. K. Color coding in a visual search task. Journal of Experimental Psychology, 1956. 51. 14.24 .

Hawkins. H. L. Paralled processing in complex visual discrimination. Perception \& Psychophysics. 1969, 5, 56-64.

Hirt. W. D. An evaluation of tive different abstract coding methods: Experiment IV. Human Factors. 1961, 3. 120-130.

LAPPIN. J. S. Attention in the identification of stimuli in complex visual displatys. Joumal of Experimental Psychology, $146 \vec{i}, 75.321 \cdot 328$.
Locher. P. J.. \& Nodine, C. F. The role of scanpaths in the recogution of random shapes. Perception \& Psychophysics. 1974. 15. 308. 314 .

LuRIA.S M. Color-name as a function of stimulus-intensity

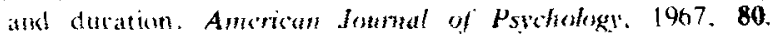
14.27.

Newman. K. M.. \& Davis, A. R. Non-redundant color, brightnest, and tlashing rate encoding of geometric symbols on a visual display. Journal of Engincering Pspchology. $1962,1,47-67$.

Noton, D., a Stark, L. Scanpaths in eye novements during pallert perception. Science. 1971a, 171, 308-311.

Noton. D.. \& Stark. L. Eye mowements and vishal perception. Scrimitic American. 14?1b. 224. 34-43.

Postman. L.. d Bruner. J. S. Multiplicity of sul as a determiner of perceptual behavior. Journal of Experimental Psychology'. 1449. 39. 364-377.

Smith. S. L. Color coding and visual search. Journal of Exprimental Psychology. 1962, 64, 434-440.

Stone. G. C. Response latencies in visual seareh involving rediudian or irrelesam information. Porecption \& Psychoplysics. 1971 a. 9. 9.14.

STONE, G. C. Individual differences in intormation processing: Compatison of simple visual stimuli. Perceptual and Motor Skills, 19716, 33, 395-414.

Tinker. M. A. Fixation patuse duration in reading. Journal of Ex/rimintul Research, 1451.44. 471-479.

Weissman. S. Etfect of luminance on the perception of red and green at various retinal positions. Journal of the Optical Siciely of America. 1965. 55. 884-887.

Weitz, J. The coding of airplane control knobs. In P. M. Hitls (ted.), Psichological research on equipment design. Wastington, D.C: U.S. Govermment Printing Office, 1947. Pp. 18:-198.

Weitzman. D. O.. \& Kinney, J. A. S. Effect of stimulus size. sharaion and rethat loxition upon the appearance of color. Joumal of the Opticul Society of America. 1969. 59. 640-643.

Witliams. L. G. The effect of target specification on objects tixalted during vistlal search. Pirception \& Psychophysics. 1966. 1. 315-318.

Writiams, L. G. The effect of larget specification on objects fixalled during visual seatch. Acta Psychologica (Ansterdam), $140 \div 27.355-360$.

Wrifjams. L. C. Sudies of exurafoxeal discrinination and detection. In Visual scarch. Washington. D.C: National Academy of Sciences. 1973. Pp. 77-42.

\section{NOTES}

1. The high perentages of relevant hixations in the CS condition are due in part to the higher proportion of relevant dials in this condition than in the $C$ and $S$ conditions.

2. In idddition to the systematic nature of the scan, one subject also exhitited this reliable characteristic: she scanned vertically rather than horizontally, and almost invariably, when she came to the lowest dial in the first column. refixated the dial above it betore moving on to the second column. Amuhe chatracteristic of the two faster scanners (C.M. and F.H.J was that they typically went past the sarget dial and had to refum. Ihis indicates of course. that processing of the target slimulus had begun during the lixation. continued while the subfect mored on, and was completed during the subsequent tivalion.

(Received for publication August 5. 1974: revision accepted Nowember 18. 1974.1 